\title{
Immune-Metabolism: Bridging Immunity and Metabolism
}

\section{Shuai Jiang*}

*Division of Biology and Biological Engineering, California Institute of Technology, Pasadena, CA 91125, USA

*Corresponding author: Jiang S, Division of Biology and Biological Engineering, California Institute of Technology, Pasadena, CA 91125, USA, Tel: 626-394-5833; Email: luckysjiang@caltech.edu

Received date: March 06, 2017; Accepted date: March 07, 2017; Published date: March 08, 2017

Copyright: (c) 2017 Jiang S. This is an open-access article distributed under the terms of the Creative Commons Attribution License, which permits unrestricted use, distribution, and reproduction in any medium, provided the original author and source are credited.

Citation: Jiang S (2017) Immune-Metabolism: Bridging Immunity and Metabolism. J Immuno Biol 2: e104. doi:10.4172/2476-1966.1000e104

\section{Editorial}

It is my pleasure to write this Editorial to announce the launch of Special Issue "Immune-Metabolism" in the Journal of Immunobiology. This Issue will cover basic and translational research about ImmuneMetabolism in human health and diseases. This issue will cover several categories of manuscripts including Reports, Article, Mini-review, and Opinion. We welcome the studies of relative underappreciated topics such as "innate-metabolism" and "adaptive-metabolism" in all physiological and pathological bioprocesses.

To meet biological demands of any immune cells, cellular metabolism fuels biological programs including activation and proliferation, while metabolic alterations are modulated by extracellular signals, mediating the direct uptake and utilization of nutrients such as glucose and glutamine [1-3]. Maintaining the functional roles of immune cells, cellular metabolism firstly provides the substrates for ATP synthesis, supporting continuous and various cellular programming of activated immune cells. Secondly, cellular metabolism supplies the building blocks for macromolecules synthesis including DNA, RNA and proteins, essential for the immune cell proliferation and activation $[4,5]$.
In this issue, we will contain the current status and challenges of cellular metabolism in all immune cells as well as how it is regulated through key modulators such as RNA-binding proteins or non-coding RNAs. We trust "Immune-Metabolism" Issue would be a favourable choice and bridge for both immunity and metabolism field. With our warmest invitations, we hope the scientists to submit their works to this issue in the journal.

\section{References}

1. Ganeshan K, Chawla A (2014) Metabolic regulation of immune responses. Annu Rev Immunol 32: 609-634.

2. O'Neill LA, Kishton RJ, Rathmell J (2016) A guide to immunometabolism for immunologists. Nat Rev Immunol 16: 553-565.

3. Nielsen J, Keasling J (2016) D. Engineering Cellular Metabolism. Cell 164: 1185-1197.

4. Brestoff JR, Artis D (2015) Immune regulation of metabolic homeostasis in health and disease. Cell 161: 146-160.

5. Grohmann U, Bronte V (2010) Control of immune response by amino acid metabolism. Immunol Rev 236: 243-264. 